\title{
Candidate Genes and Clinical-Laboratory Indices in Pregnant Women Depending on the Development of Preeclampsia
}

\author{
${ }^{1}$ Evgenii A. Reshetnikov, ${ }^{2}$ Vladimir F. Kulikovskii, ${ }^{3}$ Irina V. Batlutskaia, ${ }^{4}$ Tatiana I. Iakunchenko, \\ ${ }^{5}$ Aleksei V. Polonikov, ${ }^{6}$ Mikhail I. Churnosov \\ 1, 2, 3, 4, 6 Belgorod State University, 308015, Belgorod, Pobeda Street, 85, Russia \\ ${ }^{5}$ Kursk State Medical University, 305041, Kursk, Karl Marx Street, 3, Russia \\ e-mail: Reshetnikov@bsu.edu.ru
}

Received: 15th December 2017, Accepted: 20th December 2017, Published: 31st December 2017

\begin{abstract}
Objectives: The relationship between polymorphic variants of folate metabolism genes with clinical (blood pressure level before and at the end of pregnancy) and clinical and laboratory indicators (proteinuria, fibrinogen, total protein, urea and creatinine in the blood, activated partial thromboplastin time, thrombin time) were studied in pregnant women with preeclampsia. Materials and Methods: The study group included 322 pregnant women diagnosed with preeclampsia and 179 women with normal pregnancy. Polymorphisms of the folate cycle genes (MTHFR $+677 C>T$ (rs1801133), MTHFR +1298 A>C (rs1801131), $M T R R+66 A>G(\operatorname{rs} 1801394), M T R+2756 A>G$ (rs1805087)) were studied by real-time polymerase chain reaction (PCR) of DNA synthesis (Real-timePCR). Results: Polymorphic markers +2756 AA MTR and +1298 AC, $+1298 C C$ MTHFR are associated with an increased level of diastolic and systolic blood pressure, respectively, in women with pre-eclampsia prior to pregnancy. The genotypes $+677 S T$ and $+677 T T$ MTHFR are associated with an increased level of proteinuria, and the genetic variants of +2756 AA MTR and $+66 G G M T R R$ are associated with a lower protein content in the blood and a high proteinuria level in pregnant women with preeclampsia. Conclusions: Thus, as a result of this study, significant associations of genetic polymorphisms $M T H F R+677 C>T, M T H F R+1298$ $A>C, M T R+2756 A>G, M T R R+66 A>G$ with indices of blood pressure, protein content in the blood, proteinuria level in pregnant women with preeclampsia were determined.
\end{abstract}

Keywords: Pregnancy, Pre-eclampsia, Genetic Polymorphism, Blood Pressure.

\section{Introduction}

Preeclampsia is a multisystem pathological condition that occurs in the second half of pregnancy (after the 20th week) characterized by hypertension in combination with proteinuria, often with edema and multiple organ dysfunction (Williams et al, 2011, Sidorova, 2016). The frequency of PE is 8$20 \%$ among all pregnant women (Suhih, Murashko, 2010). During the last decade, preeclampsia is one of the main factors of perinatal morbidity in the world and stably ranks 3rd-4th in the structure of the causes of maternal morbidity and mortality (Ajlamazyan, Mozgovaya, 2010, Sidorova, 2016).

Analysis of modern literature indicates that PE is a multifactorial disease. Genetic component of PE development can account for up to $50 \%$ of all risk factors (Baranov, 2009; Reshetnikov et al., 2017). An important role in the etiology and pathogenesis of preeclampsia belongs to the candidate genes for folate metabolism (Vorozhishcheva, 2014; Zhou et al., 2016). Mutations in the genes of folate metabolism, which lead to a decrease in the activity of methyltetrahydrofolate reductase enzymes and methionine synthase reductase, lead to an excessive accumulation of homocysteine in the blood and, as a result, disruption of methylation processes in cells (Vorozhishcheva, 2014). Deficiency of folic acid causes the formation of hypertension in pregnant women, the development of total angiopathy, microthrombosis, increased insulin resistance. It should be noted that the role of candidate genes for folate metabolism in the formation of PE has been actively studied, but these studies often give conflicting results in different populations of the world (Obolenska et al., 2011; Pavlova et al., 2011; Williams et al., 2011; Valenzuela et al., 2012; Reilly et al., 2014; Vorozhishcheva, 2014;).

\section{Materials and Methods \\ Group characteristics}

According to the goals and objectives of the study, 501 women were examined: 322 pregnant women diagnosed with preeclampsia and 179 women with normal pregnancy (control group). All clinical studies were carried out according to the protocols of the ethical committee of the Russian Federation, with the informed consent of the patients. The present study includes persons of Russian nationality not being of kin to each other, born in the Central Black Earth region of Russia. Clinical and laboratory examination of women of the main and control groups was performed at the time of delivery in the Perinatal Center of St. Joasaph Belgorod Regional Clinical Hospital.

The main group included pregnant women diagnosed with preeclampsia. The diagnosis of preeclampsia was based on generalized edema, arterial hypertension and proteinuria (Sidorova, 
2016). The average age of women with PE was $27.19 \pm 6.4$ years (ranging from 18 to 44 years). The control group included pregnant women without preeclampsia aged 19 to 41 years (mean age of women was $26.71 \pm 6.36$ years) $(\mathrm{p}>0.05)$. Thus, the control group of pregnant women did not differ from the main group by sex, place of birth, age and nationality.

Exclusion criteria for the formation of the sample were: the presence of uterine pathology (uterine fibroids, internal genital abnormalities) among patients, pathology of pregnancy (abnormal attachment and location of the placenta, rhesusconflict), fetal pathology (congenital malformations), and multiple pregnancy.

Blood pressure (BP, $\mathrm{mm} \mathrm{Hg}$ ) in pregnant women was measured three times on both hands in a sitting position at intervals of one minute. The mean of the last two measurements were taken for the final BP. Data on the level of systolic and diastolic blood pressure in women before pregnancy were copied from their case records.

All pregnant women underwent the necessary laboratory examination, including: complete blood count, coagulogram, blood chemistry, common urine analysis (protein, specific gravity, epithelium, leukocytes, cylinders), Nechiporenko urine analysis, and Zimnitskii urine analysis (leukocytes, erythrocytes).

Molecular and Genetic Methods

On the basis of the Human Molecular Genetics research laboratory of Belgorod State National Research University, all pregnant women with preeclampsia and the control group were typed their polymorphic variants of folate cycle genes: methylenetetrahydrofolate reductase (MTHFR $+677 C>T$ (rs1801133), MTHFR +1298 A>C (rs1801131), methionine synthase reductase (MTRR +66 $A>G$ (rs1801394)), and methionine synthase $(M T R+2756 A>G($ rs1805087)). The material for the study was venous blood obtained in the volume of 8-9 $\mathrm{ml}$ from the ulnar vein of the pregnant women. All polymorphic variants of folate cycle enzymes were analyzed with the use of real-time DNA polymerase chain reaction (PCR) (Real-time-PCR). Statistical Methods

The formation of database and the statistical calculations were carried out using the "STATISTICA 6.0" program. Genetic and phenotypic frequencies were calculated by standard methods. The conformity of the observed distribution of genotypes to the expected one, based on the Hardy-Weinberg equilibrium, was performed using the $\chi^{2}$ criterion. In order to minimize the errors of the first kind (false positive results), the Bonferroni correction was used for multiple comparisons.

Investigation of the relations of polymorphic variants with pathogenetically significant quantitative characteristics of PE (blood pressure level, fibrinogen level, prothrombin index, etc.) was carried out using nonparametric statistics (Rebrova, 2006).

\section{Results}

As a result of the study, it was found that women with PE with genotype +2756 AA MTR have the level of diastolic blood pressure before the onset of pregnancy $\left(\mathrm{M}_{\mathrm{e}}=70.0 \mathrm{mmHg}, \mathrm{Q} 25-\mathrm{Q} 75=70.0-80.0\right.$ $\mathrm{mmHg}$ ) statistically significantly higher than that of individuals with genotypes $+2756 A G$ and $+2756 G G$ at this locus $\left(\mathrm{M}_{\mathrm{e}}=70.0 \mathrm{mmHg}, \mathrm{Q} 25-\mathrm{Q} 75=70.0-70.0\right.$ $\mathrm{mmHg}, \mathrm{p}=0.04)$. Pregnant women with $\mathrm{PE}$ with genotype +2756 AA MTR also have the level of the total protein in blood $\left(\mathrm{M}_{\mathrm{e}}=62.0 \mathrm{~g} / \mathrm{l}, \mathrm{Q} 25-\mathrm{Q} 75=60.0\right.$ $67.0 \mathrm{~g} / \mathrm{l}$ ) lower as compared to individuals with genotypes $+2756 A G$ and $+2756 G G$ for this locus $\left(\mathrm{M}_{\mathrm{e}}=64.0 \mathrm{~g} / \mathrm{l}, \mathrm{Q} 25-\mathrm{Q} 75=61.0-68.0 \mathrm{~g} / \mathrm{l}, \mathrm{p}=0.05\right)$.

Women with PE with genotypes $+1298 A C$ and +1298 SS MTHFR have the level of SBP before pregnancy $\left(\mathrm{M}_{\mathrm{e}}=110.0 \mathrm{mmHg}, \mathrm{Q} 25-\mathrm{Q} 75=110.0\right.$ $120.0 \mathrm{mmHg}$ ) and proteinuria during pregnancy $\left(\mathrm{M}_{\mathrm{e}}=0.066 \quad \mathrm{~g} / \mathrm{l} ., \quad \mathrm{Q} 10-\mathrm{Q} 90=0.033-0.160 \quad \mathrm{~g} / \mathrm{l}\right)$ statistically significantly higher than those of individuals with genotype +1298AA MTHFR $\left(\mathrm{M}_{\mathrm{e}}=110.0 \mathrm{mmHg}, \mathrm{Q} 25-\mathrm{Q} 75=110.0-115.0 \mathrm{~mm} \mathrm{Hg}\right.$; $\mathrm{p}=0.03$ and $\mathrm{M}_{\mathrm{e}}=0.066 \mathrm{~g} / \mathrm{l}, \mathrm{Q} 10-\mathrm{Q} 90=0.033-0.099$ $\mathrm{g} / \mathrm{l} ; \mathrm{p}=0.03$, respectively).

Individuals with genotype $+66 G G M T R R$ have a lower total protein level in the blood $\left(\mathrm{M}_{\mathrm{e}}=62.0 \mathrm{~g} / 1\right.$, $\mathrm{Q} 25-\mathrm{Q} 75=58.0-66.0 \mathrm{~g} / \mathrm{l}$.) compared with women with genotypes $+66 A G$ and $+66 A A M T R R\left(\mathrm{M}_{\mathrm{e}}=63.0\right.$ $\mathrm{g} / \mathrm{l}, \mathrm{Q} 25-\mathrm{Q} 75=61.0-68.0 \mathrm{~g} / \mathrm{l} ; \mathrm{p}=0.05$ ).

It was found that the level of proteinuria $\left(\mathrm{M}_{\mathrm{e}}=0.066\right.$ $\mathrm{g} / \mathrm{l}$, Q10-Q90=0.033-0.125 $\mathrm{g} / \mathrm{l})$ in pregnant women with PE with genotypes +677ST and +677TT MTHFR is higher than in pregnant women with genotype +677SS MTHFR $\left(\mathrm{M}_{\mathrm{e}}=0.066 \mathrm{~g} / \mathrm{l}\right.$, Q10$\mathrm{Q} 90=0.033-0.120 \mathrm{~g} / \mathrm{l} ; \mathrm{p}=0.04)$.

\section{Discussion}

As the results of the present study indicate, the polymorphisms of the folate metabolism genes $(M T R+2756 A>G$, MTHFR +1298 A>C, MTRR +66 $A>G$, MTHFR $+677 C>T$ ) have important pathogenetic significance in the formation of clinical and clinical laboratory parameters in pregnant women with PE. Polymorphic markers +2756 A A $M T R$ and $+1298 A C,+1298 C C$ MTHFR are associated with an increased level of diastolic and systolic blood pressure, respectively, in women with pre-eclampsia prior to pregnancy. The genotypes +677ST and + 677TT MTHFR are associated with an increased level of proteinuria, and the genetic variants of $+2756 A A M T R$ and $+66 G G M T R R$ are associated with a lower protein content in the blood and a high proteinuria level in individuals whose pregnancy had been complicated with preeclampsia. 
The following medical and biological mechanisms can be based on the revealed links of genetic polymorphisms of folate cycle genes with clinical and clinical-laboratory parameters of women with PE. According to the published data, the individuals homozygous for allele $+1298 C$ MTHFR have a decrease in the activity of MTHHRR up to $60 \%$ of the norm (Friedman et al., 1999), and those homozygous for allele $+677 T$ MTHFR have a decrease in the activity of the enzyme up to $30 \%$, heterozygous for +677ST MTHFR - up to $65 \%$ (Bailey et al., 1999). Reduction in the activity of folate cycle enzymes (methylene tetrahydrofolate reductase, methionine synthase, methionine synthase reductase) (in individuals with genetic variants +677TT, +677CT MTHFR, +1298CC MTHFR, +1298 AC) leads to disruption of the delivery and metabolism of folic acid, accumulation of homocysteine in plasma and the development of hyperhomocysteinemia (Suhovol'skaya et al., 2012). At the same time, homocysteine begins to show its toxic properties, which primarily affects the vascular walls. According to the literature, a high level of homocysteinemia (HC) is a risk factor for the development of both atherosclerotic and thrombogenic vascular lesions. An increase in the concentration of homocysteine increases oxidative stress, stimulates the production of smooth muscle cells and alters the elastic properties of the vascular wall (Strizhakov et al., 2009). Microcirculation disorders increase permeability of blood vessels, which leads to deterioration of rheological properties of blood, slowing thereby blood flow in the microcirculatory bed, increasing peripheral resistance and, as a consequence, to hypertension, which in turn increases the risk of pre-eclampsia and the severity of its manifestations (proteinuria, hypoproteinemia) (Baranov, Bolshakova, 2004).

Various studies on the search for associations of folate cycle genes with clinical and clinicallaboratory indicators in pregnant women have obtained conflicting results. Thus, in the Portuguese population, the relation of genotype $+677 T T$ MTHHRR was established with a decrease in SBP and DBP in women with gestational hypertension (Matos et al., 2013), and the study of the Yakut, Buryat and Russian populations revealed no associations of polymorphism MTHFR $+677 C>T$ with the level of blood pressure, proteinuria and hypoproteinemia in pregnant women with preeclampsia (Vorozhishcheva, 2014). A similar study of the Russian population of Central Russia also revealed no relations of the polymorphic marker of the MTHFR gene with proteinuria and arterial hypertension in pre-eclampsia (Halford-Knyazeva, 2013).

The discrepancy between the results obtained in various studies may be related to differences in the ethnic and, respectively, the genetic background of the populations under study. (Churnosov et al., 2005, Sorokina et al., 2007).

Thus, as a result of this study, significant associations of folate metabolism genes with elevated blood pressure levels in women before pregnancy, increased proteinuria and a lower protein content in pregnant women with preeclampsia were established.

\section{Conclusion}

The data obtained as a result of the research broaden the understanding of the mechanisms of preeclampsia development, and also allows predicting the nature of the clinical course of the disease, which will ensure optimization of the treatment and diagnostic process for each patient.

The polymorphisms $M T R+2756 A>G, M T H F R$ $+1298 A>C, M T H F R+677 C>T, M T R R+66 A>G$ can be used to predict blood pressure levels, proteinuria levels, and protein content in pregnant women with preeclampsia.

MTHFR $+677 C>T(\mathrm{rs} 1801133)$, MTHFR +1298 $A>C(\mathrm{rs} 1801131), M T R R+66 A>G$ (rs1801394), $M T R+2756 A>G(\operatorname{rs} 1805087))$

\section{Conflict of Interest}

The authors declare that this paper contains no conflicts of interest.

\section{References}

1. Ajlamazyan, E.K., Mozgovaya, E.V., 2008. Gestosis: theory and practice. M.: Publishing house MEDpress-inform.

2. Baranov, V.S., 2009. The genetic passport is the basis of individual and predictive medicine. StP.: Publishing House N-L.

3. Baranova, E.I., Bolshakova, O.O., 2004. Clinical significance of homocysteinemia (literature review). Arterial hypertension, 1:12-15.

4. Bailey, L., Gregory, J., 1999. Polymorphisms of methylenetetrahydrofolatereductase and other enzymes: metabolic signifi - cance, risks and impact on folate requirement. $\mathrm{J}$ Nutr, 129: 919-922.

5. Churnosov, M.I., Pesik, V.Yu., Rudyh, N.A., 2005. Materials of the study of the structure of the gene pool of the Russian population of Central Russia. Medical Genetics, 6(4): 289a-289.

6. Friedman, G., Goldschmidt, N., Friedlander, Y., Ben-Yehuda, A., Selhub, J., Babaey, S., Mendel, M., Kidron, M., Bar-On, H., 1999. Acommon mutation A1298C in human methylenetetrahydrofolatereductase gene: association with plasma total homocysteine 
and folate concentrations. J Nutr, 129: 1656-1661.

7. Halford-Knyazeva, I.P., 2013. Genetic markers for the prediction of preeclampsia: Author's abstract, PhD Medicine. M., 16.

8. Matos, A., da Silva, A.P., Maia, H., Ferreira, J., Clode, N., Areias, M.J., Bicho, M.C., Bicho, M., Rebelo, I., 2013. The polymorphism C677T of methylenetetrahydrofolate reductase (MTHFR), may increase risk for future higher blood pressure in women with previous hypertension in pregnancy. Pregnancy Hypertens, 3(2): 69.

9. Obolens'k a, M.I., Rodrihes, R.R.,2011. M artseniuk O.P. Folate-related processes in human placenta: gene expression, aminothiols, proliferation and apoptosis. Ukr Biokhim Zh, 83(1): 5-17.

10. Pavlova, K.K., Trifonova, E.A., Gotovceva, L.V., Maksimova, N.R., Nogovicyna, A.N., Stepanov, V.A., 2010. Role of polymorphisms of eNOS, ACE and MTHFR genes in the development of gestosis in the Yakut population. The Yakut Medical Journal, 3(31): 28-31.

11. Rebrova, O.Yu., 2006. Statistical analysis of medical data. The use of STATISTISA application package. M.: Publishing House Media Sfers.

12. Reilly, R., McNulty, H., Pentiev a, K., Strain, J.J., Ward, M., 2014. MTHFR 677TT genotype and disease risk: is there a modulating role for B-vitamins? Proc Nutr Soc, 73(1): 47-56.

13. Reshetnikov, E.A., Yakunchenko, T.I., Aristova, I.K., Polonikov, A.V., Churnosov, M.I., 2017. Associations of Insertion-deletion Polymorphism of Angiotensin-converting Enzyme with the Risk of Preeclampsia Development among Pregnant Women in Central Russia. Asian Journal of Pharmaceutics, 11(3): 635-639.

14. Sidorova, I.S., 2016. Preeclampsia. M.: Publishing house "Medical information agency".

15. Sorokina, I.N., Churnosov, M.I., Balanovskaya, E.V., 2007. Gene pool of the population of the Belgorod region II. "Familial portraits" in groups of regions with different levels of division and the role of migrations in their formation. Genetics, 8(43): 1120-1128.

16. Strizhakov, A.N., Makacariya, A.D., Timohina, E.V., Bajmuradova, S.M., Kozlova, U.A., 2009. Clinical significance of acquired and hereditary forms of thrombophilia in the pathogenesis of fetal growth retardation syndrome. Questions of gynecology, obstetrics and perinatology, 8(2): 16-21.

17. Suhih, G.T., Murashko, L.E., 20010. Preeclampsia. M.: Pulishing house GEOTAR-media.

18. Suhovol'skaya, M.A., Subbotina, T.N., Ol'hovskij, I.A., Bazarin, K.P., 2012. Mutations in the genes of methylenetetrahydrofolate reductase (MTHFR) and methiotine synthase (MTR) and risk factors for hyperhomocysteinemia in athletes. Clinical laboratory diagnostics, 9: 65.

19. Valenzuela, F.J., Pérez-Sepúlveda, A., Torres, M.J., Correa, P., Repetto, G.M., Illanes, S.E., 2012. Pathogenesis of preeclampsia: the genetic component. J Pregnancy, 2012: 632732.

20. Vorozhishcheva, A.Yu., 2014. Genetic factors of development of preeclampsia in populations of different ethnic origins: Author's abstract, PhD Medicine. Tomsk; 24Zainulina M.S., Glotov A.S., Korniushina M.L. Thrombophilia in obstetrical practice. StP.: Publishing house N-L. 2009.

21. Williams, P.J., Broughton, Pipkin, F., 2011. The genetics of pre-eclampsia and other hypertensive disorders of pregnancy. Best Pract Res Clin Obstet Gynaecol, 25(4): 405-417.

22. Zhou, L., Cheng, L., He,Y., Gu, Y., Wang, Y., Wang, C., 2016. Association of gene polymorphisms of FV, FII, MTHFR, SERPINE1, CTLA4, IL10, and TNFalpha with pre-eclampsia in Chinese women. Inflamm Res, 65(9): 717-724. 